\title{
The Application of Virtual Reality Technology in EFL Learning Environment in China
}

\author{
Xiangyu Chen ${ }^{1, a}$ and Meihua Chen ${ }^{1, b^{*}}$ \\ ${ }^{1}$ School of Foreign Languages, Southeast University, Nanjing, 211189, China \\ axiangyu0509@163.com, bmeihuachen123@126.com \\ * The corresponding author
}

Keywords: Virtual reality; EFL; Learning environment; TESOL

\begin{abstract}
This paper provides suggestions for the application of virtual reality technology in building EFL environment in China. The importance of authentic foreign language environment and the issue of high cost for obtaining this environment are examined. Based on the analysis of several contemporary successful cases of virtual reality online applications, a commercial gaming mode of EFL virtual reality learning and some possible design methods are suggested in the hope that the traditional EFL classes in China would benefit from this technology.
\end{abstract}

\section{Introduction}

China has a huge and increasing number of English learners. While English has mainly been taught as a subject in China for study rather than a working or living language, it has not been easy to create contexts for English practice, and the Chinese language environment has been inevitably eroding the English gaining of the EFL learners. Virtual reality (VR) is the potential solution for creating authentic language learning environment in EFL countries for several reasons. First, it could stimulate the authentic foreign environment to the target country [1]. Also, an entertainment nature of VR could possibly boost the learners' motivation of learning. What is more, VR could save the cost for transporting the learners to the real language environment, such as going to live in an English speaking country. Last but not least, VR could modify the environment for language learning, removing the irrelevant details and enlarging the positive elements for language learning.

\section{The Importance and High Cost of Authentic Learning Environment}

An authentic learning environment not only improves learning results, but also inspires learners' motivation. An authentic environment may include original English discourse, native English teachers and immersive peripheral settings, which constitute a situation where native English speakers learn their mother tongue. Empirical studies have found that VR courseware could increase EFL learners' vocabulary competence [2], and that EFL VR games could enhance learners' sense of immersion [3].The more genuine the learning environment is, the more effective the learning activities become. Unfortunately, the benefiting from this environment entails high cost.

While there are sufficient fresh original English texts, audios and videos, thanks to the Internet, for every EFL learner in China, they cannot afford a native English speaking personal tutor to practice oral English. Nor could every family afford their child to go abroad for the single purpose of English learning. According to a report by Sina.com [4], in the 2013-2014 school year, more than 270,000 Chinese overseas students are studying in the US universities, listed as the top overseas students source. Despite this remarkable figure, the majority of EFL learners in China could not enjoy this experience abroad due to the price. This is the true moment for modern technologies like VR to help the less wealthy EFL learners.

\section{Successful Virtual Reality Applications}

Virtual reality technology has long been applied, and there have been successful cases. The earliest version of virtual reality is rooted in a text-based online system, MOO (Multiple user domains 
Object-Oriented). The study of MOO applications for educational purposes has already begun early in the 1990s [5]. Its later advanced version, the massively multiplayer online role-playing games (MMORPG) are the mainstream type of serious games today, where a more vivid and highly simulated virtual world is deployed as the main game setting.

Oculus Rift is the most recently developed head-mounted display (HMD) device for VR. HMDs find their applications in military fields to give tactical information such as thermal images, and also in gaming industries to provide users with experiences of simulated real worlds. Taking language teaching into consideration, it is possible for the teachers to develop VR environment to better explain conversations than in a context that is verbally and pictorially described or even thoroughly imagined.

While building simulated 3D virtual environment may be of huge cost and long development cycle, panoramic technologies like Google Street View could offer an easier way to re-create the scenes of real world. Google Street View allows the user to see different angles of the panoramic picture and allows the user to "walk" to different standing points on the street. However, the disadvantages of street view technology are obvious: there is neither enough interactivity nor any manipulation of the objects or details of the setting. For the reason of the latter, it is hard to remove in the view the elements that may hinder the satisfactory experience of the users.

\section{Combining Gaming and EFL Learning Environment for Digital Native Learners}

While the English teachers are taking pains to discover and set the satisfactory learning environment, the VR industry, especially the gaming sector, is enjoying its everlasting boom in technology advance and users participation. Therefore, the possibility of combining the two has been brought to researchers' attention. Prensky pointed that learning games have begun to appear, such as Microsoft's "Games-to-Teach" project at MIT and LucasArts' plans on games for critical thinking [6]. To employ the power of VR into the design of foreign language learning may be easier than is anticipated, as long as some of the stereotype concepts about gaming, which is harmful and negative to the children's development, according to their parents, were changed. The approaches to combining VR and English language learning are various if the common nature of learning and gaming were fully acknowledged by parents and EFL teachers.

Learning environment design should adapt to the digital natives, the EFL students. Digital natives are those who were born in the last decades of the 20th century with the fast developing and ready-made digital technology around them [7], as opposed to digital immigrants, the generation of their parents, grandparents, or even part of the EFL teachers. In the digital natives' world, the digital devices, such as computers, PDAs, and especially smart phones of today, are almost their organs. If the digital immigrant educators try to present information to the digital native students in the traditional way, such as printed books, the students frequently respond with boredom, resistance and disbelief. VR is the next major information technology, and young students are always the ready embracers of new technologies. So it is urgent that digital immigrant educators take the initiative to change their own way of perceiving and transferring knowledge, and adjust to the pace of the digital natives.

\section{The Main Hindering Factors of Applying Virtual Reality to EFL}

It would be safe to say that VR industry would see its prosperity in the near future in various arenas, such as business, medical care, military training, and to a certainty, education. If every student and every teacher in the EFL classrooms have a smart phone in their pocket, what is the point that we stick to the printed text books? And when we try to find multimedia materials on the internet to support the texts on the book, why don't we make a multimedia presentation of the content in the first place?

The main factors hindering the applying of VR to EFL environment are the low funding and EFL teachers' low IT skills. Although the cost of software design has been reduced through the years, it is still much higher than publishing a printed book. And the schools or colleges of foreign languages 
are usually much less adequately funded than their engineering counterparts. As for the EFL teachers, they have already suffered from exploiting websites and operating computer systems, so they would not be capable of designing VR as learning environments.

\section{Commercial Mode for Virtual Reality EFL Learning Environment/Games}

If a VR learning environment could not be afforded by EFL teachers in China, it is worth a try to make it commercial. The gaming industry has always been inspiring with its successful operation modes. Taking the most popular MMO (Massive Multi-player Online) game World of Warcraft (WOW) for example, which falls into the category of entertaining VR, it has been thriving ever since it is created in 2004. According to Wikipedia [8], over 10 million subscribers joined the game in 2014, and a total 100 million accounts had been created since 2004; it is the "highest grossing video game of all time", with more than 10 billion dollars grossed as of 2012 . WOW is a pay-to-play game. The subscribers have to pay to maintain a playing account. WOW players buy game cards which contain certain amount of playing time allowed. It is the subscribers' payment that sustains and provides positive feedback to the pure and authentic playing environment that players could enjoy.

Commercial gaming mode is a practical approach to building EFL VR, securing both sufficient funding and learners' active participation. The current digital EFL learning environments in China, websites mostly, are usually test or textbook based. The contents are just a digital presentation of text books or test papers, abrading learners' interests and motivation. Attractive game designs for educational purpose are required [9]. VR for EFL learning needs more development effort and design initiatives, which demands serious design of plots [10] and substantial fund. In such case, commercial gaming mode becomes the natural approach for EFL VR. While most students in China could afford a smart phone these days, it is a safe bet that they and their mothers would pay to try the harmless EFL learning games.

\section{Possible Designs of Virtual Realities for EFL Learning}

VR devices like Oculus Rift could certainly find their application in EFL learning. And its developing kit allows users to design various customized virtual realities. Taking an English conversation at an information desk in a hospital for example, when the students put on the Oculus Rift, they would find themselves right in front of the desk and that the nurse is ready to answer any questions they ask. After they describe their symptoms to the microphones on the Oculus Rift, the simulated nurse would give the advised department to go. The students could walk, if there is an omnidirectional treadmill, and look to different directions and find the correct room number. This simulated hospital and the related interactive behaviors can already be achieved by today's technology. The complexity of the system rests in the detail designs, such as simulated figures, props, light and how real they appear, some of which may be extremely costly.

A less complicated approach of realizing simulated English learning environment would be the panoramic technology such as Google Street view. We could already use Google Maps or Google Earth to get the outdoor panoramic views of famous universities and scenic sights. What we need to do is to shift the cameras indoors, so the viewers could also "walk" inside large buildings like lecture halls and libraries, or small sites like shops and gyms. The cost of taking panoramic pictures is much lower than that of developing Oculus Rift VR for these same places. Every detail in the panoramic pictures is real, which is its advantage over Oculus Rift VR. However, the elements in panoramic pictures, especially those irrelevant to the learning purposes, could not be removed or manipulated as could be done in the Oculus Rift VR.

A combination of the two approaches could be used to play both their advantages. Taking an English conversation in a supermarket for example, the users could "walk" along the aisles through indoor panoramic view. When users decide to buy it and come to the cashier, they would enter the simulated VR and have an English conversation with the simulated cashier to finish the purchase. So the main part of the cost would be on the development of simulated cashier and the aisles could 
be built with panoramic view of lower cost.

\section{Conclusion}

VR technology would help advance the quality of and learners' experience from authentic EFL learning environment. While the prospect of gaming and learning is desirable, there are crucial determinants of its success, such as the cooperation between EFL teachers and VR developers and the sufficient and continuous funding. Traditional text books, printed on either paper or screens, would finally meet their decline, to give place to VR environments. Between then and now is the effort by pioneering EFL teachers and visionary investors. A learning-from-game mode and a affordable technological design would be the starting point for EFL VR industry in China.

\section{Acknowledgements}

This paper was supported by 'Jiangsu Social Science Fund' in China (14YYA001), 'the Fundamental Research Funds for the Central Universities' in China (2242016S30023), and 'the

Fundamental Research Funds for the Central Universities' in China (2242014S20073).

\section{References}

[1] K. Schwienhorst: Simulation \& gaming, Vol. 33 (2002) No.2, p.196.

[2] Y. L. Chen, J. L. Doong \& C. C. Hsu: Proc. Society for Information Technology \& Teacher Education International Conference (Chesapeake, USA, March, 2014). Vol. 2014, p.1090.

[3] Y. F. Wang, S. Petrina \& F. Feng: British Journal of Educational Technology, Vol.2016.

[4] Information on http://edu.sina.com.cn/a/2014-11-20/0855252624.shtml

[5] E. Crump: High wired: On the design, use, and theory of educational MOOs, (1998), p.177.

[6] M. Prensky: Computers in Entertainment (CIE), Vol. 1 (2003) No.1, p.21.

[7] M. Prensky: On the horizon, Vol. 9 (2001) No.5, p. 1.

[8] Information on http://en.wikipedia.org/wiki/World_of_Warcraft

[9] H. Söbke, T. Bröker \& O. Kornadt: Proc. European Conference on Games Based Learning (Porto, Portugal, October 3-4, 2013). p.521.

[10]R. Anyaegbu, W. Ting-JESSY \& Y. I. Li: TOJET: The Turkish Online Journal of Educational Technology, Vol. 11(2012) No.1, p.154. 